FACTA UNIVERSITATIS

Series: Mechanical Engineering Vol. 18, No 3, 2020, pp. 491 - 511

https://doi.org/10.22190/FUME200426030H

Original scientific paper

\title{
EVALUATION OF IRANIAN SMALL AND MEDIUM-SIZED INDUSTRIES USING THE DEA BASED ON ADDITIVE RATIO MODEL - A REVIEW
}

\begin{abstract}
Malek Hassanpour
Department of Environmental Science, UCS, Osmania University, Telangana State, India

Abstract. Data Envelopment Analysis (DEA) is a prominent procedure in the decisionmaking process with a pivotal role in the Sustainable Development (SD) assay. Project identification is the first step of sustainability assessment in the Environmental Impact Assessment (EIA) program for the industrial projects prior to complete establishment. The present review research comprised 405 Iranian industries assessment regarding both input and output criteria via the DEA integrated with the ratio model of Additive Ratio ASsessment (ARAS) and weighing systems of both Kendall and Friedman's tests supported by SPSS software. The findings deployed a classification for Iranian industries pertaining to industries' nominal capacity in certain clusters. Also, the current review paved the pathway towards executing both energy and materials streams in industries.
\end{abstract}

Key Words: Iranian Industries, DEA, EIA, ARAS Model, Assessment

\section{INTRODUCTION}

The current era, which scholars call the modern world, is characterized by continual change and complexity of structures. In such a situation, only the managers, i.e. those having the right, up-to-date and comprehensive information on how their organization operates, can succeed in making timely and accurate decisions for its continual improvement in line with existing changes [1]. With the expansion of organizations and increasing the supervisory scope of managers, evaluation and control of organizational units become a necessity for managers, which is not possible without evaluating the performance and efficiency of the units under their supervision as well as the evaluation by legal organizations in the EIA program [2, 3]. The DEA is a good instrument for evaluating the performance of an organization in both the EIA program and after [4].

Received April 26, 2020 / Accepted July 10, 2020

Corresponding author: Malek Hassanpour

Department of Environmental science, UCS, Osmania University, Hyderabad - 500007, Telangana State, India

E-mail: malek.hassanpour@yahoo.com 
The DEA is based on a series of optimizations using linear programming also called nonparametric methods. In the DEA, efficient boundary curves are generated from a series of points determined by linear programming [5]. The linear programming method, after a series of optimizations, determines whether the decision-maker unit is inside or outside the performance boundary. In this way, efficient and inefficient units are separated based on inputs and outputs variables. Defining inputs will be easy to compute and analyze for singleinput-output units, but in most real-world problems we have units with multiple inputs and outputs; therefore, we require methods that combine inputs and outputs. Outputs as a single indicator achieve a good benchmark for measuring efficiency $[6,7]$.

In the DEA model with an input perspective, we seek to obtain technical inefficiencies as a proportion that must be reduced in the inputs so that the output remains unchanged while the unit is at the performance boundary. We need to increase outputs without changing the inputs until the unit reaches the performance limit. In the CCR model of the DEA, the values obtained for performance in the two perspectives are equal, unlike in the BCC model where these values are different. The reason for choosing the perspective for a DEA model is in the relative evaluation of the performance of units, which in some cases has no control over unit management. The output has no variable and its value is already fixed. On the contrary, in some cases, the input is fixed and the output is variable; in such case the output view is appropriate. Inputs and outputs depending on the circumstances of the manager control are determined. Scale efficiency represents the link between changes in inputs and outputs of a system. One of the capabilities of the DEA method is to apply different patterns corresponding to the returns to different scales as well as to measure the returns to unit scales including fixed and variable scale returns. A) Fixed Scale Returns: That is, every multiple of inputs produces the same multiplier of outputs. The CCR model assumes constant scaling of outputs. B) Variable Scale Returns: That is, any multiple inputs can produce the same multiple outputs, less or more of it in the outputs $[8,9]$.

In many studies, the criteria used in the research have multiple units (dimensions) that need to be unscaled because it is not possible to use equations for different scaling parameters. One way of finding unscaled data is by using the ratio based systems that include a large number of systems like the ARAS model. The ARAS model is recently introduced as a step beyond the simplicity of the Simple Additive Weighting (SAW) model. The word ARAS means evaluating the cumulative ratio. This method is also used to rank research options. The decision matrix of this method is also an optional criterion matrix, the matrix whose columns are the criteria and its rows are the research options. Given that the author's study has shown that the DEA has had different results in the ratio models, it is, therefore, recommended that similar studies encompassing different scales with impossibility of converting the scale to currency apply a normalization system for ranking alternatives [10]. The non-scaling process with the equations introduced in ranking systems is a way of integrating parameters and options. The difficulty that appeared in shifting units to currency gets back to variations observed in materials stream entered into industrial cycles [11-13]. So by the present review study, we aimed at tabulating whole materials and energy streams in a variety of scales. Then we have assigned weighting and ranking models in order to classify and prioritize alternatives, criteria, and options. 


\section{ENVIRONMENTAL IMPACT ASSESSMENT}

EIA of projects is an environmental management practice. The search for environmental management instruments in developing countries and transition economies is itself a search for SD practices. Many engineering projects play a major role in the production and dissemination of pollution, which plays a very important role in the destruction of the environment. Large-scale impacts are considered in the final environmental threshold assessment, and these effects are likely to be large-scale, global, and to the greatest possible form. This method limits the range of pressures that can disable an ecosystem in its prime and equilibrium conditions. It examines the structure from different aspects, time, quantity, quality, spatial dimensions, and their current and future status. It covers the stages of social and environmental assessment including evaluation, mitigation, impact monitoring, and auditing. Comprehensive EIA has the following four characteristics such as:

- Integration with local or national decision-making processes,

- Integration with environmental management approaches and instruments,

- Integration with the evaluation process, and

- Integration with economic, social, health and environmental impacts.

In Iran, the ultimate goal of EIA is to achieve SD in the form of economic programs consistent with the principles of environmental protection as well as to prevent destruction and depletion of renewable and non-prescriptive resources. EIA includes the following steps: (1) Screening, (2) Estimating the scope of work, (3) Determining the evaluation report, (4) Review, and (5) Monitoring. According to the International Union of EIA views, the process of carrying out an environmental assessment includes the following stages: (1) Screening, (2) Determining the scope of work, (3) Testing options, (4) Impact analysis, (5) Corrective actions and managing effects, (6) Evaluation of index cases, (7) Reporting, (8) Review, (9) Decision-making, and (10) Future corrections. Screening is a process that determines whether or not there is a need to perform an evaluation and its level. The three general screening criteria are the type of project or development priorities, project size, and project location. The following project executives are also required to carry out a feasibility report and assessment in the EIA program [14]. (1) Petrochemical plants on any scale (2) The petrochemical refinery on any scale (3) The power plant with a production capacity of more than 100 Megawatt (4) Steel industries (5) Large dams and aquatic structures or a lateral structure larger than 40 hectares or a lake area of more than 400 hectares (6) Irrigation projects larger than 5000 hectares (7) Tailing dam of any size (8) Industrial estates over 100 hectares (9) Airport with a runway length greater than 2000 meters (10) Agro-industrial units over 5,000 hectares (11) Large industrial slaughterhouses (12) Landfills for provincial and city centers larger than 200,000 inhabitants and new cities (13) Landfill Centers (Compost Factory etc.) (14) Oil and gas pipeline designs, oil rigs, oil storage sites, forestry plans, highways, railways, tourism projects (15) Related industrial and service plans (16) Construction workplaces larger than 10,000 square meters (17) Land reclamation (18) Accommodation, development of river basins and rural roads. 
EIA is a process that ensures that all environmental matters are taken into account quite early in the project at planning itself. It takes into consideration not only technical, financial and economic considerations but also traditional aspects like impacts on local people, biodiversity, etc. EIA is intended to prevent or minimize potential adverse environmental impacts and enhances the overall quality of a project [15]. The main benefits and advantages of EIA are: Lower project costs in the long-term, increased project acceptance, improved project design, informed decision-making, environmentally sensitive decision, increased accountability and transparency, reduced environmental damage, improved integration of projects into their environmental and social settings.

EIA methodology means the structural approaches for doing one or more activities of EIA. There are some specific characteristics that an EIA methodology should depict. It should be appropriate to the necessary task of the EIA process such as impact identification/comparison of alternatives and significantly free from the assessors' bias. It should be economical in terms of costs, as well as of its requirement of data, investigation of time, personnel, equipment, and facilities. Impact identification attempts to answer the question of what will happen when a project enters its operational stage. A list of important impacts such as changes in ambient air quality, changes in water and soil qualities, noise levels, wildlife habitats, species diversity, social and cultural systems, employment levels, etc. may be prepared. The important sources of impact like smoke emission, consumption of water and discharge of effluent, etc. are identified. Impact evaluation aims to assign relative significance to predicted impacts associated with the projects and to determine the order in which impacts are to be avoided, mitigated or compensated.

EIA methods encompassed many practices and models such as three-dimension matrix, Leopold matrix, Patterson matrix, Achieve to objectives matrix, time matrix, effective size matrix, weighting matrix, Saratoga matrix, Favorite matrix, Pastakia matrix, Monavari method, workshop models, Flowdiagrams systems, Networks, Delphi fuzzy logic, Optimal path method, Internal method, Threshold analysis method, Natural threshold method, Audit, Expert method, checklist method, questionnaires, overlays method, Mongol method, Ad-Hoc method, and Battle method, etc. [16,17]. The decision-making process is an integral part of the EIA program including lots of multi-criteria decision-making (MCDM) models [11, 18].

Recently, the use of MCDM systems containing a variety of variables increased in lots of developing sciences individually or integrated with other models. In the 44 stock market selection used the DEA-COPRAS method along with the Entropy Shannon weighing system for 61 months in India. The return values of each stock have been taken into consideration in currency. By the way, 18 stock markets selected to go through the efficiency assessment steps. The ranking system arranged to assort the companies based on the inputs and outputs criteria in currency [19]. Azadi et al. [20] prioritized the 24 green suppliers via the fuzzy double frontier DEA model in Iran. Using the combined VIKOR and DEA models resulted in the estimation of efficiency scores about multiple inputs and outputs. To cope with environmental challenges for the $\mathrm{CO}_{2}$ dissipation, scientists used the DEA model to estimate the efficiency of emission permissions considering minimum outlays in 29 Chinese provinces. The quantities of pollutants reported in $\mathrm{CO}_{2}$ (10 thousand tons), gross domestic product (100 million RMB), electricity consumption (100 million $\mathrm{KWH}$ ), total investment in fixed assets (100 million RMB) [21]. To investigate the footprint of greenhouse gasses, ozone formation and acidification ability caused by European Union manufacturing sectors exploited the DEA model based on the dissipation rate in currency. The dissipation rate has 
been reported as $\mathrm{CO}(\mathrm{t}), \mathrm{CO}_{2}(\mathrm{t}), \mathrm{CH}_{4}(\mathrm{t}), \mathrm{N}_{2} \mathrm{O}(\mathrm{t}), \mathrm{NOx}(\mathrm{t}), \mathrm{SO}_{2}(\mathrm{t}), \mathrm{NH}_{3}(\mathrm{t})$, volatile organic compounds $(\mathrm{t})$ [2]. The research investigated the Chinese industries' eco-efficiency based on the exploitation of energy and dissipation of environmental pollution via the DEA model during 2006-2013. Ecological efficiency of provinces was found to be with an average rise [22]. Uniting the game theory, the DEA model and Gray system resulted in developing a model to evaluate the efficiency score of 21 various kinds of cars in Iran Khodro Company. The number of cars entered into Pre Delivery Inspection (PDI), the number of PDI personals, the number of cars exited from PDI, on-time delivery score, customer satisfaction scores were used as the criteria [23]. By research, the dynamic DEA applied to appraise the economic development efficiency in seek of $\mathrm{CO}_{2}$ dissipation falls out of $28 \mathrm{EU}$ countries in a period from 2009-2013. The input variables devoted to the labor force, real capital stock, energy consumption, fossil fuel consumption and $\mathrm{CO}_{2}$ emissions allocated for output variables [24].

With regard to the division done upon the collected data, it was classified as two classes of variables of input and output in the research by Bulak and Turkyilmaz [25]. Input variables included proximity to market, ability to control costs, potential labor force, product quality, prompt advantage, certification, distribution channel, pricing policy and service, capital and machinery equipment track ended up to outputs of market share and net profit margin. The performance efficiency of around 744 small and medium enterprises showed 94 efficient industries in Turkey. With regard to some criteria such as store territory, population density, total hours worked by in-store personnel, total hours worked by delivery personnel and weekly expenses, the research considered the use a hybrid approach united with Fuzzy Analytic Hierarchy Process (AHP), DEA and TOPSIS models to assess the retail efficiency by Duman et al [26]. The performance of the supply chain of pharmaceutical companies scrutinized using the DEA model supported by factor analysis in the Tehran Stock Exchange. The questionnaires' passed out to 115 experts and they gathered the data for the survey. Findings gave a high performance for 12 of the 28 resources investigated [27]. Research pursued the performance of China's 31 grid companies via DEA and Tobit regression at a time interval of 2004 to 2013. The results showed a rise in efficiency scores during the period. Anthony et al [28], assessed the performance of 7 Indian chemical companies via the traditional DEA model along with the weighing system of the Friedman test. The criteria reported in currency and composed the frameworks of output and input variables. A range of efficiency scores was found to be between 0 and 1 with high propinquity among companies in terms of the DEA score. The thirty-seven regional and national Iranian refinement and oil product distribution companies including two inputs and three outputs criteria underwent the DEA model and weighted with both entropy and AHP. So, the classification of companies was done in the arranged procedure in Iran [29]. Azadi et al [30] extended a united DEA enhanced Russell measure model in fuzzy ambient concerning SD ingredients such as economic, social and environmental to choose the best suppliers among 26 cases in Iran. The nineteen facility layout difficulties were evaluated by the DEA model in the study of Toloo et al [31] via inputs and outputs criteria such as cost, adjacency score and shape ratio, flexibility, quality, and hand-carry utility, respectively. According to the research, the efficiency weights led to the classification of alternatives and removed the problem in Iran. The twenty-two Indian oil and gas companies scored against efficiency scale analysis using the DEA model depend on materials consumed, employee benefit expenses, capital investment, operating revenue and profit after tax as input and output 
criteria [32]. The petrochemical industry evaluated for the efficiency score classification based on 5 inputs and 5 outputs criteria via 5 DEA models and AHP (weighing system) in Saudi Arabia [33]. Unearthing sustainable technology with the use of the DEA model was investigated by Kim et al [34] from 1980 to 2010. A study examined the efficiency evaluation using DEA model supplemented by AHP about inputs and outputs criteria such as distance from $\mathrm{Co}_{2}$ source, minimum flow rate requirement (input), injectivity limit, operating life, product yield, product value, sequestration parameter, reservoir capacity, well security and structural integrity (outputs) [35]. The semiconductor industry evaluated the efficiency steps by the DEA model based on 2 inputs values and one output value [36]. To estimate the efficiency of seven bus operators paid attention to fuel cost, labor cost, depreciation expense, other costs, patronage volume, mileage and satisfaction index in Nanjing, China. The values reported in currency and then based on mentioned costs applied the DEA model to rank the options and AHP to weight the criteria [37]. Also Nemati and Matin [38], Saravi et al., [39], Ulengin et al., [40], Sevinc and Eren [41] and Woo et al., [42] used the DEA model for resource allocation for 60 firms, location selection for the co-firing biomass plants, resources exploitation of 82 automotive companies and operational efficiency of shipping industries regarding lots of criteria and alternatives, respectively. The present review targeted to evaluate 405 Iranian industries via DEA based on the additive ratio model in the EIA of projects with notice to some recent studies carried out in this regard.

\section{PROJECT IDENTIFICATION STEPS}

The methodology employed by the present review refers to conjoining the traditional DEA model with a newly introduced model of ARAS in compliance with the SAW model. According to the current rules of the Iranian environment protection agency and Iranian industries organization, the engineering projects should traverse the project identification stage in the EIA with encompassing the screening of project properties [43]. The screening of all industrial projects obviously manifests the energy demands, input and output materials flow, the required staff, labors and whole aspects of economic estimation of projects. The weighting systems employed included both Friedman and Kendall tests due to a full agreement with emerging the highest weights for the highest values and vice versa. Zavadskas et al [44] used the Kendall test as a weighing system in MCDM models of TOPSIS, COPRAS, and ARAS to select technological options for installing pilecolumns (driving the rings) in the construction operation. ARAS model also provided an excellent coherency with the Traditional DEA model according to our experience during the research. There is no propinquity between the integration of the traditional DEA model with other additive ratio models [45]. Therefore, to complete the initial screening of the Iranian evaluator team for 405 Iranian small and medium-sized industries, they have undergone further processing of their ranking and weighing. The findings appeared in the current review published by a few research papers; then we tried to collect main achievements at present review paper. The mentioned steps to complete the review and project identification levels of Iranian evaluator team are displayed in Fig. 1. 


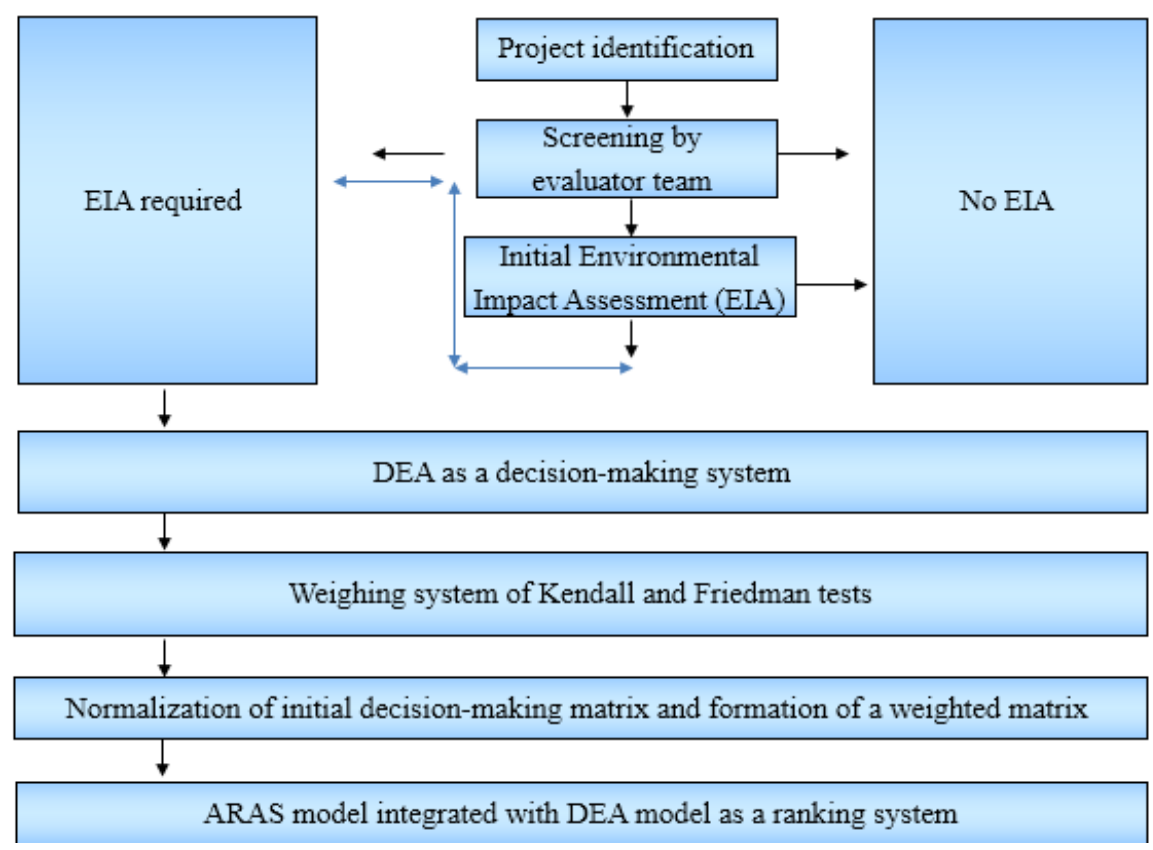

Fig 1. The flow-diagram of followed work

The collected data are tabulated with regard to inputs materials flow, Nominal Capacity (NC) of industries and 5 main criteria such as the number of staff, power, water, fuel demands and the land area required to construct industries individually. The NC and input materials flow that is called Initial Feed (IF) included a variety of values in miscellaneous scales such as NC $(\mathrm{t}), \mathrm{NC}(\mathrm{No}), \mathrm{NC}$ (pocket), NC $\left(\mathrm{m}^{2}\right), \mathrm{NC}(\mathrm{m}), \mathrm{NC}(\mathrm{Skin}), \mathrm{NC}\left(\mathrm{ft}^{2}\right), \mathrm{NC}($ Pair), NC (jean), NC (Yard), NC (barrel), NC (L), NC (crank), NC (bottles) and IF (t), IF (No), IF ( $\left.\mathrm{m}^{2}\right), \mathrm{IF}(\mathrm{m}), \mathrm{IF}$ (L), IF (mm), IF (pair), IF $\left(\mathrm{m}^{3}\right), \mathrm{IF}$ (sheet), IF (pieces), IF (Bundle), IF (Rolls), IF ( $\left.\mathrm{ft}^{2}\right), \mathrm{IF}$ (thread), IF (yard) and IF (duke). To understand the variables composing the framework of the present review, they depicted in an illustration format. The input and output criteria that design the framework of the DEA model are illustrated according to Fig. 2.

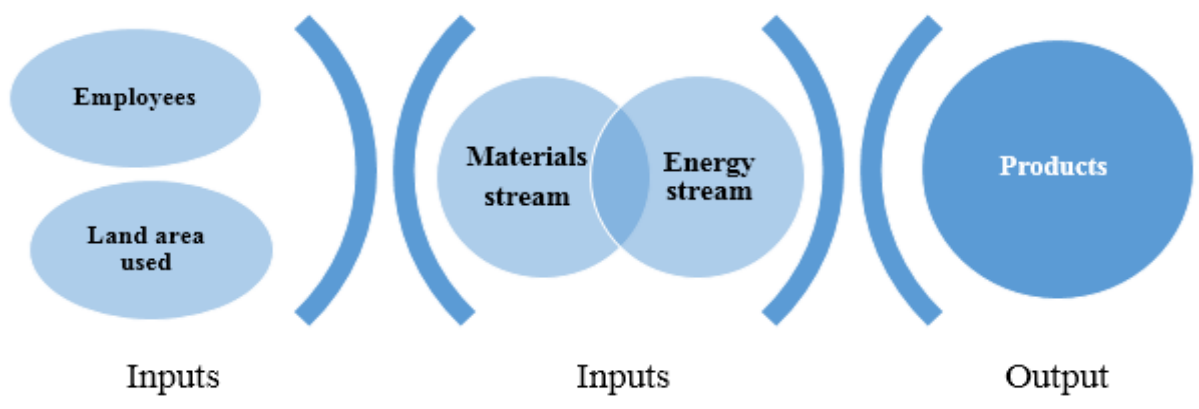

Fig. 2 Input and output criteria of DEA model 
The values of Weights (W) are calculated by both the Friedman and Kendall tests using SPSS software. Then the vector of $\mathrm{W}$ is introduced into normalized criteria in the ARAS system to sum the $\mathrm{W}$ of alternatives (industries) individually. Finally, the weighted average of NC to weighted average of IF released the weights for the alternatives; then the ranking system set based on W. In this case, the Iranian industrial productivity was investigated to decide in economic growth parallel with political dimensions to expand via DEA based on additive ratio models. The AHP sought to determine the values of $\mathrm{W}$. The manpower, remuneration, capital, labor, energy, new investment and value-added were taken into consideration as inputs and outputs in a period [50]. Also, Azar et al [51] used a novel DEA based on the additive ratio model to estimate the ordinary set of $\mathrm{W}$ by explaining the procedure via an example. So, Iranian industries are classified in certain clusters according to below descriptions based on NC. It needs to explain that all tabulated amounts for energy and materials streams are reported in annual estimation and for the industries before construction.

\section{IRANIAN INDUSTRIES}

By the present review, 9 groups (including 405 industries) of Iranian industries passed through the DEA-ARAS model to classify the industries based on materials and energy streams such as Iranian Wood and Cellulose Industries (IWCI; 16 various types), Iranian Textile and Leather Industries (ITLI; 38 various types), Iranian Mining and Aggregate Industries (IMAI; 26 various types), Iranian Food Industries (IFI; 57 various types), Iranian Automotive Industries (IAI; 71 various types), Iranian Plastic Industries (IPI; 21 various types), Iranian Electronic Products Manufacturing Industries (IEPMI; 33 various types), Iranian Chemical Industries (ICI; 118 various types) and Iranian Household Appliance Industries (IHAI; 25 various types). There is no similar study to cover the same implication and concept in this field but in the case of similar studies, they can be related to the cases below.

Amini and Alinezhad [52] asserted that his request to use the DEA model to rank 15 Iranian industries succeeded to score 8 efficient industries holding a score of 1 . A study completed by Lu et al., [53] included a method approach to DEA to find the performance of many units of industries. The efficiency scores of the 34 Chinese life insurers companies evaluated via the DEA model included 5 criteria during the period from 2006 to 2010. The DEA score ranged from 0.905 to 0.973. Iranian regional power companies of Azerbaijan, Isfahan, Bakhtar, Tehran, Khorasan, Khuzestan, Zanjan, Semnan, Sistan, Gharb, Fars, Kerman, Gilan, Mazandaran, Hormozgan, and Yazd have undergone the efficiency assessment via a novel DEA model. The designed method was also examined with other models to get acceptance for the efficiency analysis as well as its reliability in the mentioned assessment. The power companies got an efficiency score based on input and output stream analysis [54]. A study scrutinized around 23 main manufacturing units via the DEA model during the period from 2005-2007. By the way, the industries passed through the efficiency analysis along with the identification of the provinces where engulfed the utmost performance of industries. The minimum and maximum ranges of DEA scores placed the industries in an interval of 0 to 1 [55]. The results of using the DEA model to assess the efficiency level of manufacturing plants of China and Turkey opened the door to demystify the performance of industries between two countries with Chinese industries placed in the first rank. It needs to explain that canonical correlation was employed as a weighting system 
for both input and output criteria [56]. Keramidou et al [57] assessed the efficiency of the Greek meat products industry using the DEA model in a period from 1994 to 2007. The findings have proved the inefficiency of industries with a rise due to mismanagement and prodigality of the asset. Also, 59 Iranian manufacturing units underwent efficiency analysis via the DEA in terms of the amount of fossil fuel, water, electricity consumption, employee's payment and technical efficiency by Rezaee and Ghanbarpour [58] and in a time interval from 1995-2009.

\section{THE VALUES OF W FOR CRITERIA}

A wide variety of 405 small and medium-sized industries has led to the emergence of different kinds of input and output materials with weight units in Iran. A sample from each industry has been studied and reported. The complexity of input materials introduced into industries makes it impossible to convert input and output materials into currency in such studies as well as complexity in identifying commercial name, number of labels and their purity. Therefore, the best option for managing the materials is to report them in different units of measurement. The energy consumed and a land area used along with employees number were included as well as the remaining part of input factors in a variety of dimensions. But the output materials of industries which are called industry products were reported as NC different in terms of measurement scales or dimensions. Therefore, the tabulated values make the frameworks of criteria to calculate the values of $\mathrm{W}$.

Table $1 \mathrm{~W}$ values for criteria of IWCI, IMAI, and IFI [46, 47]

\begin{tabular}{|c|c|c|c|c|c|}
\hline IWCI & W & IMAI & $\mathrm{W}$ & IFI & W \\
\hline $\mathrm{NC}(\mathrm{t})$ & 12.81 & $\mathrm{NC}(\mathrm{t})$ & 10.92 & IF (t) & 8.58 \\
\hline $\mathrm{NC}$ (pocket) & 6.06 & $\mathrm{NC}\left(\mathrm{m}^{2}\right)$ & 3.94 & IF (No) & 10.16 \\
\hline $\mathrm{NC}\left(\mathrm{m}^{2}\right)$ & 6.88 & Employees & 7.77 & $\mathrm{IF}(\mathrm{L})$ & 3.84 \\
\hline $\mathrm{NC}(\mathrm{m})$ & 6.13 & Power (kw) & 9.50 & IF (pieces) & 3.70 \\
\hline Power (kw) & 16.94 & Water $\left(\mathrm{m}^{3}\right)$ & 7.25 & $\mathrm{IF}(\mathrm{m})$ & 4.04 \\
\hline Employees & 14.66 & Fuel $(\mathrm{Gj})$ & 7.40 & $\operatorname{IF}\left(\mathrm{m}^{3}\right)$ & 3.85 \\
\hline Fuel (Gj) & 13 & Land $\left(\mathrm{m}^{2}\right)$ & 11.31 & $\mathrm{NC}$ (bottles) & 3.88 \\
\hline Water $\left(\mathrm{m}^{3}\right)$ & 12.75 & $\mathrm{IF}(\mathrm{t})$ & 11.77 & $\mathrm{NC}(\mathrm{No})$ & 5.32 \\
\hline Land $\left(\mathrm{m}^{2}\right)$ & 13.88 & IF (No) & 6.19 & $\mathrm{NC}(\mathrm{t})$ & 7.39 \\
\hline $\operatorname{IF}(\mathrm{t})$ & 10.94 & IF (L) & 3.69 & Employees & 10.94 \\
\hline $\operatorname{IF}\left(\mathrm{m}^{3}\right)$ & 6.63 & $\mathrm{IF}(\mathrm{m})$ & 3.98 & Power (Kw) & 13.23 \\
\hline IF (Bundle) & 6.03 & $\operatorname{IF}\left(\mathrm{m}^{2}\right)$ & 3.83 & Water $\left(\mathrm{m}^{3}\right)$ & 9.96 \\
\hline $\mathrm{IF}(\mathrm{No})$ & 11.38 & $\operatorname{IF}\left(\mathrm{m}^{3}\right)$ & 3.44 & Fuel $(G j)$ & 10.79 \\
\hline $\mathrm{IF}(\mathrm{m})$ & 7.03 & & & Land $\left(\mathrm{m}^{2}\right)$ & 9.32 \\
\hline IF (Rolls) & 6.63 & - & - & & - \\
\hline $\operatorname{IF}\left(\mathrm{m}^{2}\right)$ & 7.25 & - & - & - & - \\
\hline $\mathrm{IF}(\mathrm{L})$ & 5.97 & - & - & - & - \\
\hline IF (pieces) & 6.06 & - & - & - & - \\
\hline
\end{tabular}


Tables 1 to 3 included the values of $\mathrm{W}$ for criteria of IAI, IPI, IEPMI, ICI, IHAI, ITLI, IWCI, IMAI, and IFI. As mentioned above, the values of $\mathrm{W}$ for the criteria are estimated by SPSS software using both Friedman and Kendall's tests. The Friedman and Kendall's tests are used to compare a variety of groups to find the ranks among them. Introducing non-parametric criteria allows the software to investigate the homogeneity of variances of a variety of data in groups. There are lots of empirical equations to estimate the values of $\mathrm{W}$ without applying software. The Iranian evaluator teams employed some experimental and empirical equations with a strong base in science and technology in order to estimate the initial values for the inputs and outputs composing the DEA framework. Therefore, conducting the consistency and reliability tests in the following Friedman or Kendall tests does not seem common in such studies because the quantities are neither changeable nor have been recognized as expert ideas. But homogeneity of data is a prominent point. Kendall's W can support the findings and analysis of the Friedman test and can be employed for evaluating agreement among values. So, a high agreement is distinguished among the initial values of data for all groups using Kendall's W test [59, 60].

Table 2 The W values for criteria of ITLI, and IAI [46, 47]

\begin{tabular}{|c|c|c|c|}
\hline ITLI & W & IAI & W \\
\hline $\mathrm{NC}(\mathrm{t})$ & 11.29 & IF (t) & 9.87 \\
\hline $\mathrm{NC}(\mathrm{No})$ & 13.71 & IF (No) & 15.46 \\
\hline $\mathrm{NC}\left(\mathrm{m}^{2}\right)$ & 10.75 & IF (L) & 5.24 \\
\hline $\mathrm{NC}(\mathrm{m})$ & 10.36 & $\mathrm{IF}(\mathrm{mm})$ & 5.06 \\
\hline NC (Skin) & 9.26 & $\operatorname{IF}\left(\mathrm{m}^{2}\right)$ & 5.89 \\
\hline $\mathrm{NC}\left(\mathrm{ft}^{2}\right)$ & 9.68 & $\mathrm{IF}(\mathrm{m})$ & 5.89 \\
\hline NC (Pair) & 10.11 & $\mathrm{IF}\left(\mathrm{m}^{3}\right)$ & 4.98 \\
\hline $\mathrm{NC}$ (jean) & 9.29 & IF (sheet) & 4.99 \\
\hline Employees & 22.33 & $\mathrm{NC}\left(\mathrm{m}^{2}\right)$ & 5.05 \\
\hline NC (Yard) & 9.20 & $\mathrm{NC}(\mathrm{No})$ & 14.98 \\
\hline Power (Kw) & 23.64 & $\mathrm{NC}(\mathrm{t})$ & 4.98 \\
\hline Water $\left(\mathrm{m}^{3}\right)$ & 20.29 & $\mathrm{NC}$ (pair) & 5.08 \\
\hline Land $\left(\mathrm{m}^{2}\right)$ & 20.87 & Employees & 14.10 \\
\hline $\operatorname{IF}\left(\mathrm{m}^{2}\right)$ & 10.37 & Power (Kw) & 15.46 \\
\hline $\mathrm{IF}(\mathrm{m})$ & 10.30 & Water $\left(\mathrm{m}^{3}\right)$ & 12.13 \\
\hline IF (No) & 18.38 & Fuel (Gj) & 11.45 \\
\hline IF (duke) & 9.07 & Land $\left(\mathrm{m}^{2}\right)$ & 12.39 \\
\hline $\mathrm{IF}(\mathrm{L})$ & 10.03 & & \\
\hline IF (pair) & 9.53 & & \\
\hline IF (yard) & 9.67 & & \\
\hline IF (thread) & 9.11 & & \\
\hline $\mathrm{IF}\left(\mathrm{ft}^{2}\right)$ & 10.16 & & \\
\hline $\mathrm{IF}(\mathrm{t})$ & 18.16 & & \\
\hline Fuel (Gj) & 20.22 & & \\
\hline IF (Sheet) & 9.24 & & \\
\hline
\end{tabular}


Due to the ease of application and high precision and accuracy of SPSS software to estimate the values of $\mathrm{W}$, the criteria took the values in Tables 1 to 3. Also, the criteria initially provided the simple use of the decision model of ARAS-DEA to normalize and uniform rates to offer an appropriate decision-making model for industry classification consequently efficiency score $[59,60]$.

Table 3 The W values for criteria of IPI, IEPMI, ICI, and IHAI [47-49, 11, 45]

\begin{tabular}{|c|c|c|c|c|c|c|c|}
\hline IPI & $\mathrm{W}$ & IEPMI & $\mathrm{W}$ & ICI & $\mathrm{W}$ & IHAI & W \\
\hline IF $(t)$ & 8.02 & $\mathrm{NC}(\mathrm{t})$ & 4.59 & $\mathrm{NC}(\mathrm{t})$ & 9.58 & $\mathrm{IF}(\mathrm{t})$ & 3.9 \\
\hline IF (No) & 7.4 & NC (No) & 13.17 & NC (No) & 8.8 & IF (No) & 10 \\
\hline $\operatorname{IF}\left(\mathrm{m}^{2}\right)$ & 4.05 & $\mathrm{NC}\left(\mathrm{m}^{2}\right)$ & 4.56 & $\mathrm{NC}\left(\mathrm{m}^{2}\right)$ & 5.84 & $\mathrm{IF}\left(\mathrm{m}^{2}\right)$ & 2.24 \\
\hline $\mathrm{IF}(\mathrm{m})$ & 5.05 & $\mathrm{NC}$ (barrel) & 4.38 & $\mathrm{NC}(\mathrm{m})$ & 5.79 & $\mathrm{IF}(\mathrm{m})$ & 2.82 \\
\hline IF (pair) & 4.57 & NC (crank) & 4.61 & $\mathrm{NC}\left(\mathrm{m}^{3}\right)$ & 5.87 & $\mathrm{NC}(\mathrm{No})$ & 8.24 \\
\hline $\mathrm{NC}\left(\mathrm{m}^{2}\right)$ & 4.52 & Employees & 12.89 & NC (Pair) & 5.79 & $\mathrm{NC}(\mathrm{t})$ & 2.4 \\
\hline $\mathrm{NC}(\mathrm{No})$ & 6.98 & Power $(\mathrm{Kw})$ & 14 & $\mathrm{NC}(\mathrm{L})$ & 5.69 & Employees & 8.12 \\
\hline $\mathrm{NC}(\mathrm{t})$ & 5.93 & Water $\left(\mathrm{m}^{3}\right)$ & 11.28 & Employees & 15.30 & Power (Kw) & 9.7 \\
\hline $\mathrm{NC}$ (pair) & 4.12 & Land $\left(\mathrm{m}^{2}\right)$ & 10.88 & Power $(\mathrm{Kw})$ & 17.11 & Water $\left(\mathrm{m}^{3}\right)$ & 6.04 \\
\hline Employees & 11.69 & $\operatorname{IF}\left(\mathrm{m}^{2}\right)$ & 6.09 & Water $\left(\mathrm{m}^{3}\right)$ & 13.66 & Fuel (Gj) & 5.82 \\
\hline Power $(\mathrm{Kw})$ & 12.90 & $\mathrm{IF}(\mathrm{m})$ & 6.2 & Land $\left(\mathrm{m}^{2}\right)$ & 13.71 & Land $\left(\mathrm{m}^{2}\right)$ & 6.72 \\
\hline Water $\left(\mathrm{m}^{3}\right)$ & 9.74 & IF (No) & 15.66 & $\operatorname{IF}\left(\mathrm{m}^{2}\right)$ & 6.06 & - & - \\
\hline Fuel (Gj) & 9.57 & IF (L) & 4.5 & $\mathrm{IF}(\mathrm{m})$ & 6.04 & - & - \\
\hline Land $\left(\mathrm{m}^{2}\right)$ & 10.45 & IF (pair) & 4.97 & IF (No) & 12.54 & - & - \\
\hline- & - & $\operatorname{IF}(t)$ & 8.45 & $\mathrm{IF}(\mathrm{L})$ & 6.85 & - & - \\
\hline- & - & Fuel (Kw) & 9.77 & IF (pair) & 5.68 & - & - \\
\hline \multirow[t]{2}{*}{-} & - & - & - & $\mathrm{IF}(\mathrm{t})$ & 12.50 & - & - \\
\hline & & & & Fuel (Gj) & 14.09 & - & - \\
\hline
\end{tabular}

The assay accomplished upon the $\mathrm{W}$ values for criteria showed the highest correlation around 0.872 between both groups of IFI and IPI industries with no significant differences among the values of $\mathrm{W}$ for the criteria of 9 group industries. The sequence diagrams typically do not display a regular graphical functionality of the values of $\mathrm{W}$ for criteria.

\section{THE VALUES OF W IN THE RANKING SySTEMS}

The ranking systems applied to the classification of Iranian industries produced values for the alternatives considering the criteria. To sum up, the DEA-ARAS model resulted in the below $\mathrm{W}$ values. Figs. 3 to 5 display the values of $\mathrm{W}$ in the ranking system for each cluster industry individually.

Assigning the ARAS model to the values of outputs and inputs streams containing different scales resulted in normalizing the values and uniting the quantities to appear as a sum via introducing special vectors of the values of criteria $\mathrm{W}$ separately for both inputs and outputs streams in industries. The division of output quantities to input quantities released the values of $\mathrm{W}$ in the ranking system. The highest values were devoted to industries of 7, 19 and 12 for the IHAI, IPI and IMAI according to Fig. 3, respectively. It conducted the same procedure for the remaining industries groups. 


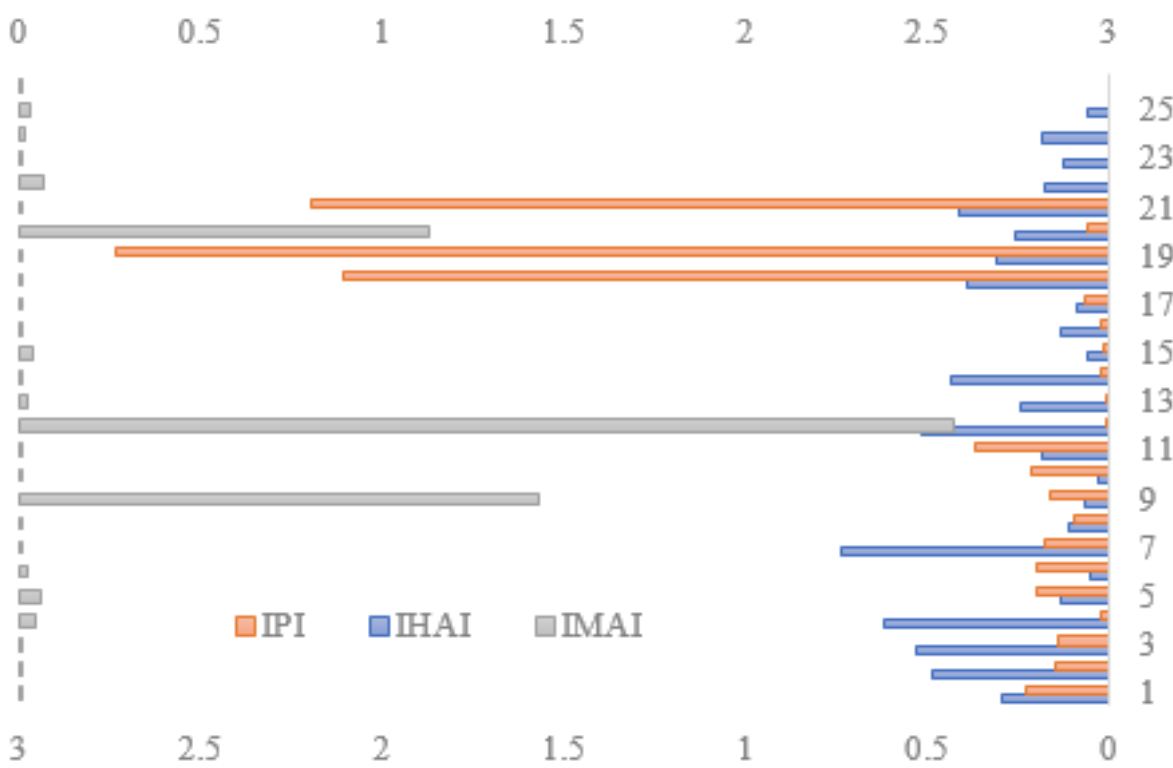

Fig. 3 The values of W in the ranking system for IPI, IHAI, and IMAI [11, 46, 49]

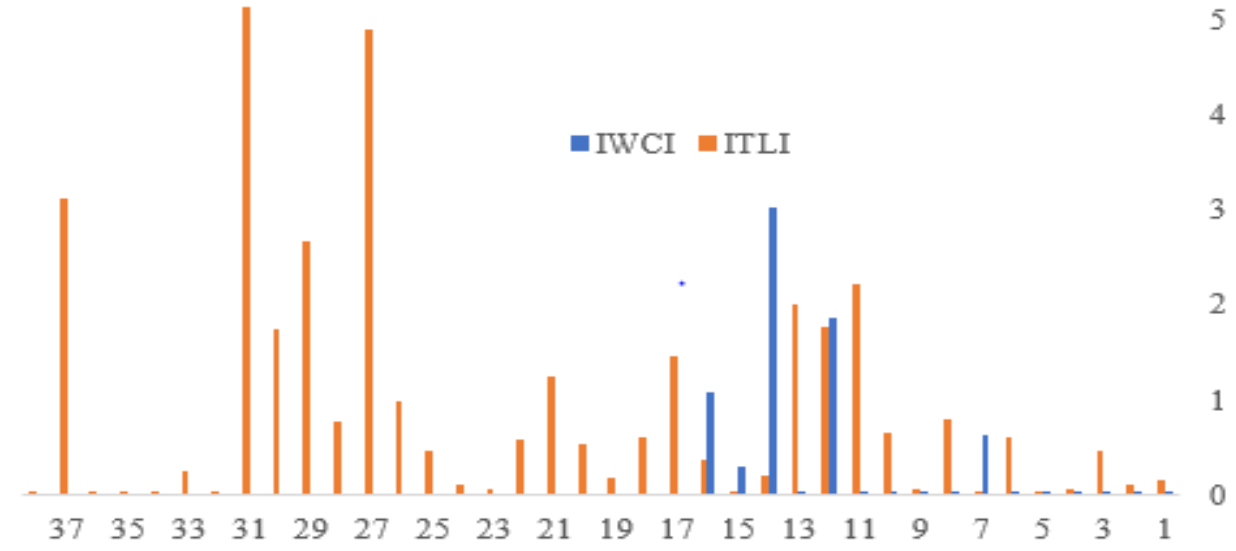

Fig 4 The values of W in the ranking system for IWCI and ITLI [46]

According to Fig. 4, the highest values of $\mathrm{W}$ belong to industries 14 and 31 for the IWCI and ITLI, respectively. Also, the highest values of W were devoted to industries 21 , 10 and 30 for IAI, IFI, and IEPMI in Fig. 5, respectively. 


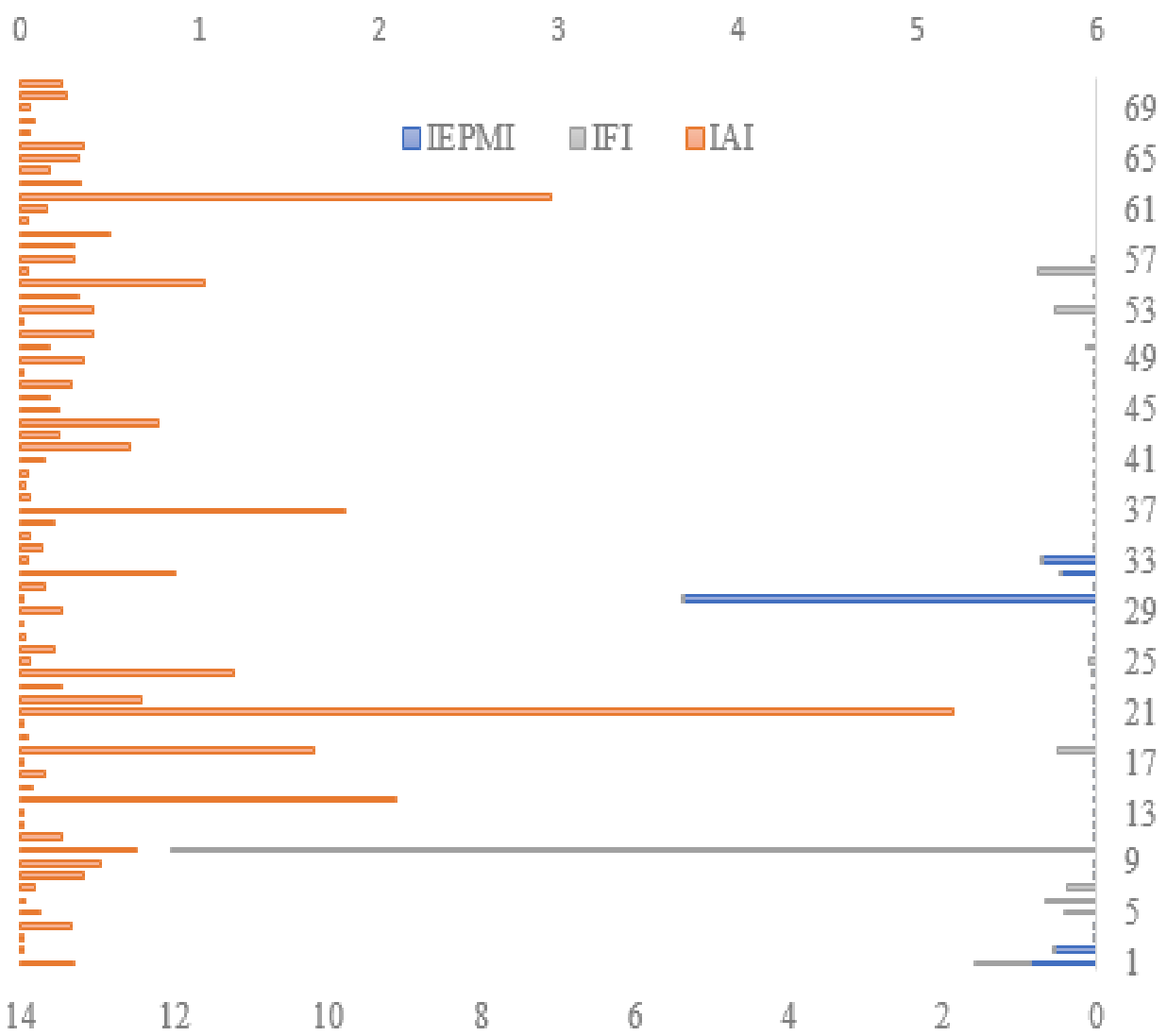

Fig 5 The values of W in the ranking system for IEPMI, IFI and IAI [47, 48]

ICI encompassed a variety of industries dealing with the processing of chemical products. This cluster also comprises IPI industries in a certain cluster. But the homogeneity of data and propinquity of project availability in terms of technologies and materials characteristics led to composing a separate cluster for the IPI. The diversity of the values of $\mathrm{W}$ encouraged the display of the values in Table 4.

There is a significant difference around ( $\mathrm{p}$-value $\leq 0.003$ ) for the ICI among the values of W of ITLI, IMAI, IWCI, IFI, IAI, IPI, IEPMI and IHAI by conducting t-test. Also, the highest correlation of about 0.672 was observed between the values of $\mathrm{W}$ of IAI and IWCI via the Pearson correlation (sig. 2 tailed) test. 
Table 4 Values of W in the ranking system for ICI [11]

\begin{tabular}{|c|c|c|c|c|c|}
\hline Industry & ICI & Industry & ICI & Industry & ICI \\
\hline 1 & 0.1253 & 41 & 0.0341 & 81 & 0.0920 \\
\hline 2 & 0.0422 & 42 & 0.0195 & 82 & 0.07768 \\
\hline 2 & 0.0420 & 43 & 1.2130 & 83 & 0.0476 \\
\hline 4 & 2.1930 & 44 & 0.0319 & 84 & 0.0186 \\
\hline 5 & 0.0059 & 45 & 0.0353 & 85 & 0.0016 \\
\hline 6 & 0.0131 & 46 & 0.0004 & 86 & 6.8818 \\
\hline 7 & 0.0113 & 47 & 0.0281 & 87 & 0.0414 \\
\hline 8 & 0.0455 & 48 & 0.0089 & 88 & 0.0293 \\
\hline 9 & 0.0056 & 49 & 0.0504 & 89 & $5.17 \mathrm{E}-05$ \\
\hline 10 & 0.1411 & 50 & 0.0809 & 90 & 0.0004 \\
\hline 11 & 0.0126 & 51 & 0.0653 & 91 & 0.0018 \\
\hline 12 & 0.3291 & 52 & 0.0152 & 92 & 0.0749 \\
\hline 13 & 11.526 & 53 & 0.0156 & 93 & 0.0032 \\
\hline 14 & 9.08E-05 & 54 & 0.4197 & 94 & 0.0463 \\
\hline 15 & 0.0033 & 55 & 0.1217 & 95 & 0.2009 \\
\hline 16 & 0.0021 & 56 & 0.0044 & 96 & 0.0705 \\
\hline 17 & 0.0183 & 57 & 0.07583 & 97 & 0.0552 \\
\hline 18 & 0.0344 & 58 & 0.0010 & 98 & 0.0661 \\
\hline 19 & 0.0089 & 59 & 0.0387 & 99 & 0.0115 \\
\hline 20 & 0.0237 & 60 & 0.1119 & 100 & 0.0084 \\
\hline 21 & 0.0042 & 61 & 0.0037 & 101 & 0.01194 \\
\hline 22 & 0.0044 & 62 & 0.0843 & 102 & 0.1188 \\
\hline 23 & 0.02185 & 63 & 3.6973 & 103 & 0.0221 \\
\hline 24 & 1.9378 & 64 & 0.1663 & 104 & 0.0012 \\
\hline 25 & 0.0088 & 65 & 0.0207 & 105 & 3.2977 \\
\hline 26 & 0.2593 & 66 & 0.1006 & 106 & 0.5322 \\
\hline 27 & 0.0240 & 67 & 0.5428 & 107 & 0.0164 \\
\hline 28 & 0.1432 & 68 & 0.1102 & 108 & 0.0054 \\
\hline 29 & 0.0298 & 69 & 0.1123 & 109 & 0.3924 \\
\hline 30 & 0.3892 & 70 & 0.0069 & 110 & 0.0090 \\
\hline 31 & 0.0513 & 71 & 0.1267 & 111 & 13.810 \\
\hline 32 & 0.0196 & 72 & 0.0648 & 112 & 1.1911 \\
\hline 33 & 0.01233 & 73 & 0.0426 & 113 & 0.1967 \\
\hline 34 & 0.0092 & 74 & 0.0358 & 114 & 0.0582 \\
\hline 35 & 0.0598 & 75 & 0.0312 & 115 & 0.0646 \\
\hline 36 & 0.0073 & 76 & 4.3707 & 116 & 4.3686 \\
\hline 37 & 16.449 & 77 & 0.3729 & 117 & 0.0306 \\
\hline 38 & 0.0008 & 78 & 0.3351 & 118 & 0.0881 \\
\hline 39 & 0.8077 & 79 & 0.0032 & & \\
\hline 40 & 0.2202 & 80 & 0.0133 & & \\
\hline
\end{tabular}

\section{DEA RANK DEVELOPED FOR 9 GROUPS OF INDUSTRIES}

At first industries' information was normalized by the equations of the ARAS model and then the values of $\mathrm{W}$ were released by both Friedman and Kendall tests assigned to alternatives (industries) in order to collect the final $\mathrm{W}$ in the ranking system for the outputs and inputs criteria separately. As discussed above, the weighted average of output divided to the weighted average of inputs generated a numeric value representing the 
calculated value for the DEA. Since the raw data reported by the Iranian evaluator team is for all the industries under study, these industries were classified into specific clusters $(9$ clusters). Therefore, the DEA rank displays for industries via Figs. 6 to 8 .

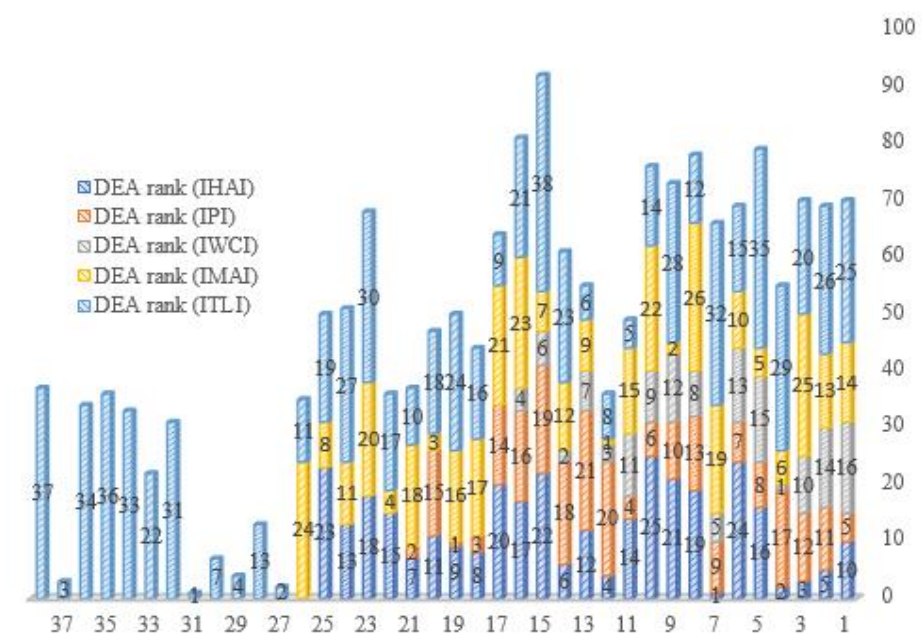

Fig 6 The DEA rank developed for ITLI, IMAI, IWCI, IPI, and IHAI [46, 45, 49]

According to Fig. 6, the highest DEA rank was assigned to industries 31, 12, 4, 19 and 7 for ITLI, IMAI, IWCI, IPI and, IHAI, respectively. The highest DEA rank means the industry holding the highest value of $\mathrm{W}$ and vice versa.

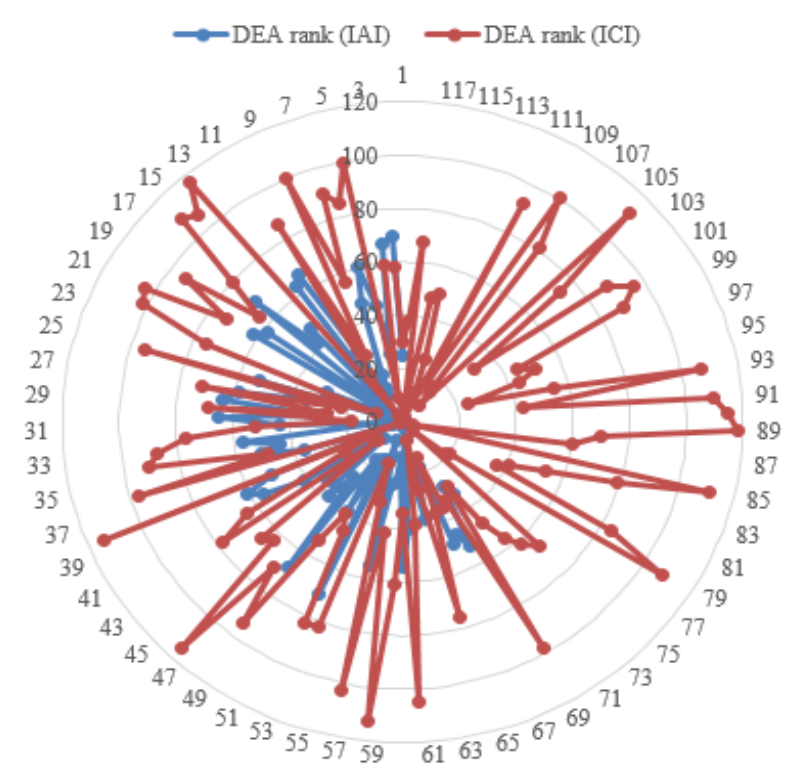

Fig 7 The DEA rank developed for ICI and IAI [11, 47] 


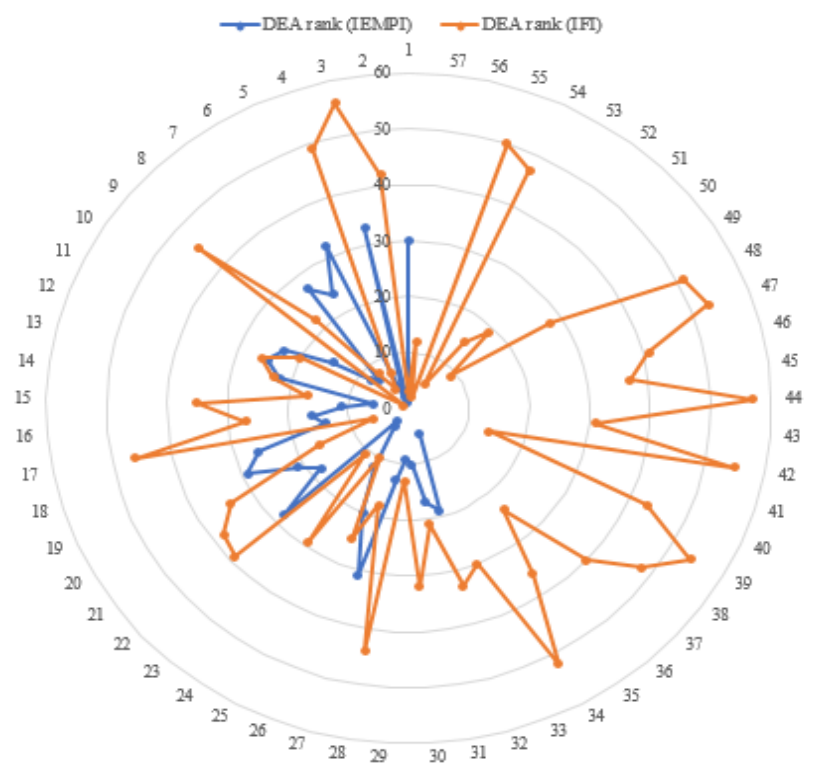

Fig 8 The DEA rank developed for IEMPI and IFI [48, 47]

According to Figs. 7 and 8, the highest DEA rank was allocated to industries 37, 10, 21, and 2 for ICI, IFI, IAI, and IEMPI, respectively. Clearly, the charts classified 405 Iranian industries into 9 groups from the highest to lowest rank according to their annual energy and materials intake. The number of employees required annually is also one of the input factors considered in the calculation by the DEA. To prove the findings the DEA-ARAS model conducting a sensitivity analysis based on other MCDM models does not seem a reasonable experience because the results are very different for any model (like ARAS) in connection or integration with the traditional DEA model. But the DEA based on other additive ratio models can pursue the objective for determining the efficiency score and classifying industries in similar studies.

A variety of reports pointed out that the DEA model is an overwhelming procedure for measuring the operational and managerial performance of industries etc. [61]. For instance, the DEA model was assigned to find the efficiency score of fifteen insurance companies in a time interval from 2005 to 2012. So, despite identifying the efficient companies, it showed dramatic variations between the values of technical efficiency estimated in the mentioned period [62]. The study by Izadikhah et al. [63] determined the efficiency score of 17 suppliers depending on sustainability aspects such as economic, environmental and social factors encompassing 41 criteria. Also, Mirhedayatian et al. [64] employed a novel dualfactor DEA model for supplier selection of 10 companies regarding about 5 main criteria and 26 factors. Assessment of the efficiency of wind turbines applied a two-sub process DEA model in China. By the way, the models took into consideration wind turbines depend on power generation efficiency [65]. A study managed to estimate the efficiency of around 40 retail stores of cloth companies using the DEA model for a time interval from 2010-2013. The technical efficiency employed the regression analysis in the following steps [66]. To select and thrift the appropriate complex product systems of industries suppliers dilated a 
DEA model. The mentioned model has taken into account the economic, geographic and technical criteria to estimate the productivity in the optimum cost-effective situation. The attempt to examine the criteria sought the selection of the best suppliers among them [67]. To appraise the sustainability of milk packaging systems (PrePack, Composite box, Tetra Pak considering the crude oil and natural gas consumption rates, $\mathrm{CO}_{2}$, Coal, Electricity and recycled materials) for commodities about fitness in terms of environmentally friendly aspects the DEA model has taken into consideration [68]. The Greek meat products investigated the efficiency score via the DEA model from 1994 to 2007. So, mismanagement conveyed the industries towards inefficiency levels and mostly the wastage of assets [57]. The study performed by Abri and Mahmoudzadeh [69], Mehdiabadi et al [70], Asayesh and Raad [71] and Azbari et al. [27] utilized the DEA, DEA-TOPSIS, DEA, and DEA to appraise the impact of information technology on productivity and efficiency, the rank of efficient units, evaluation of the relative efficiency and supply chain performance in 23 Iranian manufacturing industries during 2002-2006, 15 various sectors of industries, gas stations, and one certain Iranian pharmaceutical industry, respectively. So, the achievements noticed to IT had a positive and statistically significant effect on the productivity of manufacturing industries; 8 efficient units of chemical industries could be considered as the most attracting industries for investment, raking gas station, along with hierarchical classification and latent variable had the highest correlation with supply chain performance and 12 of the 28 supply chains obtained 1 as the highest performance rate and the lowest cases around 0.81 , respectively. Therefore, the literature proves the vast application of DEA techniques in other sciences and techniques [72].

\section{CONCLUSION}

To the best of our knowledge, this is the first report and research which encompassed whole Iranian industries passing through the DEA model prior to complete construction. The DEA model was found as a strong decision-making model. The present review used the traditional DEA model united with the ARAS model to release the efficiency score due to the presence of various criteria containing different scales. The efficiency score besets the energy consumed and materials entered into industries loops. The prioritization of industries is a way towards classification of existing and upcoming industries pertaining to NC. Calculating the values of $\mathrm{W}$ via software found the best procedure with high accuracy and precision in this regard. Shifting the criteria worth in currency is a suggestion for forthcoming research projects. Also, developing any novel and modern technique can be taken into consideration in future studies. The defined input and output criteria can be considered along with intermediate options to deploy new and complex models of the DEA and explore efficiency in a more enhanced way.

Likewise, the industry's information is a useful resource of energy and materials streams and the best media to deploy the relevant database to the comparison of industries at local and global levels depending on the NC and running technologies. Accordingly, this review provides a benchmarking for the classification of all industries before construction for future plans in the EIA program as well as paving the way towards simplicity in economic and financial studies as well as offering the frameworks of SD for effective expansion. The role of evaluator teams is highlighted by the current study in the 
screening plan of the EIA program. Additionally, the importance of database designing is clear for both the Iranian industry's organization and the Iranian environment protection agency. The energy and materials stream management allocates a way for the industrial ecology and industries development.

Acknowledgments: This research was conducted as part of the corresponding author Ph.D. research work (Entitled; Evaluation of 405 Iranian Industries). The funding information is not applicable to the present paper.

\section{REFERENCES}

1. Mensah, E.K., 2019, Robust optimization in data envelopment analysis, PhD Thesis, University of Insubria Department of Economics, Varese - Milano.

2. Zurano-Cervello, P., Pozo, C., Mateo-Sanz, J.M., Jimenez, L., Guillen-Gosalbez, G., 2018, Ecoefficiency assessment of EU manufacturing sectors combining input-output tables and data envelopment analysis following production and consumption-based accounting approaches, Journal of Cleaner Production, 174, pp. 1161-1189.

3. Baker, M.J., 2003, The marketing book, Fifth Edition, Butterworth-Heinemann An imprint of Elsevier Science Linacre House, Jordan Hill, Oxford OX2 8DP, Chapter 9, pp. 1-875.

4. Kuçukonder, H., Demirarslan1, C.P, Burgut, A., Boga, M., 2019, A Hybrid Approach of Data Envelopment Analysis Based Grey Relational Analysis: A Study on Egg Yield, Pakistan J. Zool, 51(3), pp. 903-912.

5. Anouze, A.L., Osman, I.H., 2014, Mismanagement or mis-measurement: the application of DEA to generate performance values and insights from big data, methodologies, tools, and applications, chapter 6, pp. 276-322.

6. Pastor, J.T., Ruiz, J.L., Sirvent, I., 1999, A statistical test for detecting influential observations in DEA, European Journal of Operational Research, 115, pp. 542-554.

7. Cheraghali, Z., Papi, S., 2017, Investigating the performance of the healthcare sector in the provinces of Iran by using a window analysis in data, Int. J. Data Envelopment Analysis, 5(3), pp. 1353-1360.

8. Mardani, A., Zavadskas, E.K., Streimikiene, D., Jusoh, A., Khoshnoudi, M., 2017, A comprehensive review of data envelopment analysis (DEA) approach in energy efficiency, Renewable and Sustainable Energy Reviews, 70, pp. 1298-1322.

9. Tabatabaei, M.H., M., Amiri., Ghahremanloo, M., Keshavarz-Ghorabaee, M., Zavadskas, E.K., Antucheviciene, J., 2019, Hierarchical decision-making using a new mathematical model based on the best-worst method, International journal of computers communications \& control, 14(6), pp. 710-725.

10. Kaklauskas, A., Zavadskas, E.K., 2015, Multiple criteria analysis of the life cycle of the built environment, Monograph, Funded by European Social Fund, pp. 1-448

11. Hassanpour, M., 2020, Evaluation of Iranian small and medium-sized industries, A Ph. D thesis submitted to Osmania University, Telengana state, India.

12. Gerami, J., 2017, An extended of multiple criteria data envelopment analysis models for ratio data, Int. J. Data Envelopment Analysis, 5(4), pp. 1361-1386.

13. Vahidi, H., Hoveidi, H., Kazemzadeh, Khoie, J., 2016, Challenges and Opportunities of Industrial Ecology Development in Iran, Int. J. Environ. Res., 10(2), pp. 217-226.

14. Glasson, J., Therivel, R., Chadwick, A., 2005, Introduction to environmental impact assessment, 2nd edition, Taylor \& Francis e-Library, USA.

15. Aravossis, K.G., Kapsalis, V.C., Kyriakopoulos, G.L, Xouleis, T.G., 2019, Development of a Holistic Assessment Framework for Industrial Organizations, Sustainability, 11, pp. 1-24.

16. Munn, R.E., 1979, Environmental Impact Assessment, Principles and Procedures, Scope 5, John Wiley and Sons, New York.

17. Zwikael, O., Chih, Y.Y., Meredith, J.K., 2018, Project benefit management: Setting effective target benefits, International Journal of Project Management, 36, pp. 650-658.

18. Amini, A., Alinezhad, A., 2016, A combined evaluation method to rank alternatives based on VIKOR and DEA with BELIEF Structure under Uncertainty, Iranian Journal of Optimization, 8(2), pp. 111-122. 
19. Gupta, S., Bandyopadhyay, G., Bhattacharjee M, Biswas, S., 2019, Portfolio selection using DEACOPRAS at risk - return interface based on NSE (India), International Journal of Innovative Technology and Exploring Engineering (IJTTEE), 8(10), pp. 4078-4086.

20. Azadi, M., Mirhedayatian, S.M., Saen, R.F., Hatamzad, M., Momeni, E., 2017, Green supplier selection: a novel fuzzy double frontier data envelopment analysis model to deal with undesirable outputs and dual-role factors, Int. J. Industrial and Systems Engineering, 25(2), pp. 160-181.

21. An, Q., Wen, Y., Xiong, B., Yang, M., Chen, X., 2017, Allocation of carbon dioxide emission permits with the minimum cost for Chinese provinces in big data environment, Journal of Cleaner Production, 142, pp. 886-893.

22. Xiong, B., Li, Y., Song, M., 2017, Eco-efficiency measurement and improvement of Chinese industry using a new closest target method, International Journal of Climate Change Strategies and Management, 9(5), pp. 666-681.

23. Tabasi, M., Navabakhsh, M., Kotobashkan, H., Tavakkoli-Moghaddam, R., 2019, Performance evaluation using network data envelopment analysis approach with game theory under mixed grey-fuzzy uncertainty in Iran Khodro Company, International Transaction Journal of Engineering, Management, \& Applied Sciences \& Technologies, 10 (13), pp. 1-19.

24. Lu, C.C, Lu, L.C., 2019, Evaluating the energy efficiency of European Union countries: The dynamic data envelopment analysis, Energy \& Environment, 30(1), pp. 1-17.

25. Bulak, M.E., Turkyilmaz, A., 2014, Performance assessment of manufacturing SMEs: a frontier approach, Industrial Management \& Data Systems, 114(5), pp. 797-816.

26. Duman, G.M, Tozanli, O., Kongar, E., Gupta, M.S., 2017, A holistic approach for performance evaluation using quantitative and qualitative data: A food industry case study, Expert Systems with Applications 81, pp. 410-422.

27. Azbari, M.E., Olfat, L., Amiri, M., Soofi, J.B., 2014, A network data envelopment analysis model for supply chain performance evaluation: real case of Iranian pharmaceutical industry, International Journal of Industrial Engineering \& Production Research, 25(2), pp. 125-137.

28. Anthony, P., Behnoee, B., Hassanpour, M., Pamucar, D., 2019, Financial performance evaluation of seven Indian chemical companies, Decision Making: Applications in Management and Engineering, 2(1), pp. 19-37.

29. Shafiee, M., Amirzadeh, M., 2011, Evaluating Performance of the 37 areas of N.I.O.P.D.C using a mathematical model, 3rd International Conference on Information and Financial Engineering IPEDR vol.12, IACSIT Press, Singapore.

30. Azadi, M., Jafarian, M., Saen, R.F., Mirhedayatian, S.M., 2015, A new fuzzy DEA model for evaluation of efficiency and effectiveness of suppliers in sustainable supply chain management context, Computers \& Operations Research, 54, pp. 274-285.

31. Toloo, M., Tavana, M., Santos-Arteaga, F.J., 2019, An integrated data envelopment analysis and mixed integer non-linear programming model for linearizing the common set of weights, CEJOR, 27, pp. 887-904

32. Bansal, V.R., 2018, Efficiency evaluation of Indian oil and gas sector: data envelopment analysis, International Journal of Emerging Markets, 14(2), pp. 362-378.

33. Alidrisi, H., Aydin, M.E., Bafail, A.O., Abdulal, R., Karuvatt, S.A., 2019, Monitoring the Performance of Petrochemical Organizations in Saudi Arabia Using Data Envelopment Analysis, Mathematics, 7, pp. 1-16.

34. Kim, J.M., Sun, B., Jun, S., 2019, Sustainable technology analysis using data envelopment analysis and state space models, Sustainability, 11(3), pp. 2-19.

35. Tapia, J.F.D., Promentilla, M.A.B., Tseng, M.L., Tan, R.R., 2017, Screening of carbon dioxide utilization options using hybrid Analytic Hierarchy Process-Data Envelopment Analysis method, Journal of Cleaner Production, 165, pp. 1361-1370.

36. Tsai, C.H., Wu, H.Y, Chen, I.S., Chen, J.K., Ye, R.W., 2017, Exploring benchmark corporations in the semiconductor industry based on efficiency, Journal of High Technology Management Research, 28, pp. 188-207.

37. Li, X., Liu, Y., Wang, Y., Gao, Z,. 2016, Evaluating transit operator efficiency: An enhanced DEA model with constrained fuzzy-AHP cones, Journal of traffic and transportation engineering (English edition), 3(3), pp. 215-225.

38. Nemati, M., Matin, R.K., 2019, A data envelopment analysis approach for resource allocation with undesirable outputs: an application to home appliance production companies, Sadhana, 44, article no. 11. 
39. Saravi, N.A., Yazdanparast, R., Momeni, O., Heydarian, D., Jolai, F., 2019, Location optimization of agricultural residues-based biomass plant using Z-number DEA, Journal of Industrial and Systems Engineering, 12(1), pp. 39-65.

40. Ülengin, F., Kabak, Ö., Önsel, S., Aktas, E., \& Parker, B.R., 2011, The competitiveness of nations and implications for human development, Socio-Economic planning sciences, 45(1), pp. 16-27.

41. Sevinç, A., Eren, T., 2019, Determination of KOSGEB support models for small-and medium-scale enterprises by means of data envelopment analysis and multi-criteria decision making methods, Processes, 7(3), pp. 1-27.

42. Woo, S.H., Lai, P.L., Chen, Y.H., Yang, C.C., 2019, Meta-frontier function approach to operational efficiency for shipping companies, Maritime policy \& management, 46(5), pp. 529-544.

43. Heldman, K., 2009, Project management professional exam study guide, Fifth Edition, Copyright by Wiley Publishing, Inc., Indianapolis, Indiana Published simultaneously in Canada, pp. 1-677.

44. Zavadskas, E.K., Sušinskas, S., Daniunas, A., Turskis, Z., Sivilevicius, H., 2012, Multiple criteria selection of pile-column construction technology, Journal of civil engineering and management, 18(6), pp. 834-842.

45. Hassanpour, M., 2019, Efficiency Score Assessment of Iranian Plastic Industries, Proceedings of Business and Economic Studies, 2(5), pp. 1-5.

46. Hassanpour, M., 2019, Efficiency score assessment of Iranian Mining, Wood and Textile Industries, Iranian Journal of Optimization, 11(3), pp. 1-15.

47. Hassanpour, M., 2019, Efficiency Score Assessment of Iranian Automotive and Food Industries, Int. J. Data Envelopment Analysis, 7(2), pp. 65-82.

48. Hassanpour, M., 2019, Evaluation of Iranian electronic products manufacturing industries using an unsupervised model, ARAS, SAW and DEA models, Journal of Industrial Engineering and Management Studies, 6(2), pp. 1-24.

49. Hassanpour, M., Pamucar, D., 2019, Evaluation of Iranian household appliance industries using MCDM models, Operational Research in Engineering Sciences: Theory and Applications, 2(3), pp. 1-25.

50. Rahmani, M., 2017, A productivity analysis of Iranian industries using an additive data envelopment analysis, Management Science Letters, 7, pp. 197-204.

51. Azar, A., Mahmoudabadi, Z.M, Emrouznejad, A., 2016, A new fuzzy additive model for determining the common set of weights in Data Envelopment Analysis, Journal of Intelligent \& Fuzzy Systems, 30, pp. 61-69.

52. Amini, A., Alinezhad, A., 2016, A combined evaluation method to rank alternatives based on VIKOR and DEA with belief structure under uncertainty, Iranian Journal of Optimization, 8(2), pp. 111-122.

53. Lu, W.M., Wang, W.K., Kweh, Q.L., 2014, Intellectual capital and performance in the Chinese life insurance industry, Omega. 42, pp. 65-74.

54. Shermeh, H.E., Najafi, S.E., Alavidoost, M.H., 2016, A novel fuzzy network SBM model for data envelopment analysis: A case study in Iran regional power companies, Energy, 112, pp. 686-697.

55. Ahmadi, V., Ahmadi, A., 2012. Application of Data Envelopment Analysis in manufacturing industries of Iran, Interdisciplinary journal of contemporary research in business, 4(8), pp. 534-544.

56. Bayyurt, N., duzu, G., 2008, Performance measurement of turkish and chinese manufacturing firms, a comparative analysis, Eurasian Journal of Business and Economics, 1(2), pp. 71-83.

57. Karamidou, J., Mimis, A., Pappa, E. 2011, Estimating technical and scale efficiency of meat products industry: the Greek Case, Journal of Applied Science, 11(6), pp. 971-979.

58. Rezaee, M.J., Ghanbarpour T., 2016, Energy resources consumption performance in Iranian manufacturing industries using cost/revenue efficiency model, IJE Transactions C: Aspects, 29(9), pp. 1282-1291.

59. Puska, A., Stojanovic, I., Maksimovic, A., 2019, Evaluation of sustainable rural tourism potential in BRCKO district of Bosnia and Herzegovina using multi-criteria analysis, Operational Research in Engineering Sciences: Theory and Applications, 2(2), pp. 40-54

60. Biswas, T.K., Chaki, S., Das, M.C., 2019, MCDM technique application to the selection of an Indian institute of technology, Operational Research in Engineering Sciences: Theory and Applications, 2(3), pp. 65-76.

61. Feroz, E.H., Kim S., Raab, RL, 2017, Financial statement analysis: a data envelopment analysis approach, Journal of the Operational Research Society, 54, pp. 48-58.

62. Sinha, R.P., 2015, A Dynamic DEA model for Indian Life insurance companies, Global Business Review, 16(2), pp. 1-12. 
63. Izadikhah, M., Saen, R.F., Ahmadi, K., 2017, How to assess sustainability of suppliers in volume discount context? A new data envelopment analysis approach, Transportation Research Part D, 51, pp. 102-121.

64. Mirhedayatian, S.M., Azadi, M., Saen, R.F., 2014, A novel network data envelopment analysis model for evaluating green supply chain management, Int. J. Production Economics 147, pp. 544-554.

65. Niu, D., Song, Z., Xiao, X., Wang, Y., 2018, Analysis of wind turbine micro-siting efficiency: An application of two-sub-process data envelopment analysis method, Journal of Cleaner Production, 170, pp. 193-204.

66. Xavier, J.M., Moutinho, V.F., Moreira, A.C., 2015, An empirical examination of performance in the clothing retailing in-dustry: A case study, Journal of Retailing and Consumer Services, 25, pp. 96-105.

67. Solgi, O., Gheidar-Kheljani, J., Saidi-Mehrabad, M., Dehghani, E., 2019, Implementing an efficient data envelopment analysis method for assessing suppliers of complex product systems, Journal of Industrial and Systems Engineering, 12(2), pp. 113-137.

68. Xie, Y., Gao, Y., Zhang, S., Bai, H., Liu, Z., 2019, Sustainability evaluation of product packaging system with a three-stage network data envelopment analysis methodology, Appl. Sci, 9, pp. 246, 1-16.

69. Abri, A.G., Mahmoudzadeh, M., 2015, Impact of information technology on productivity and efficiency in Iranian manufacturing industries, J Ind Eng Int, 11, pp. 143-157.

70. Mehdiabadi, A., Rohani, A., Amirabdollahiyan, S., 2013, Ranking industries using a hybrid of DEATOPSIS, Decision Science Letters, 2(4), pp. 251-256.

71. Asayesh, R., Raad, Z.F., 2014, Evaluation of the relative efficiency of gas stations by data envelopment analysis, International Journal of Data Envelopment Analysis and Operations Research, 1(1), pp. 12-15.

72. Xie, B.C., Gao, J., Chen, Y.F., Deng, N.Q., 2018, Measuring the efficiency of grid companies in China: A bootstrapping non-parametric meta-frontier approach, Journal of Cleaner Production, 174, pp. 1381-1391. 